\title{
LA ARGUMENTACIÓN COMO RESOLUCIÓN DE PROBLEMAS EN EL DISCURSO NEOCORPORATIVISTA DE POLÍTICAS VENEZOLANAS (1989- 1994). ANÁLISIS CRÍTICO.
}

\author{
Alicia Pineda*
}

RECIBIDO: Julio 2018 / ACEPTADO: Abril 2020 / PUBLICADO: Mayo 2020

Como citar: Pineda, Alicia. (2020). La argumentación como resolución de problemas en el discurso neocorporativista de políticas venezolanas (1989-1994). Análisis crítico. Telos: revista de Estudios Interdisciplinarios en Ciencias Sociales, 22 (2), Venezuela. (Pp.445-461).

DOI: www.doi.org/10.36390/telos222.14

\section{RESUMEN}

Se analiza críticamente el discurso de Planes de desarrollo en Venezuela (1989-1994) con la finalidad de develar las estrategias argumentativas que justifican ideológicamente las políticas formuladas por el Fondo Monetario Internacional (FMI) en el contexto de aplicación del modelo neocorporativista de la nueva economía neoliberal. El marco teórico contempla, básicamente, los autores: Maniglio (2017), White (1999), Habermas (1999), Beaugrande y Dressler (1997), Martín y Whittaker (1995), Charaudeau (1992) y Pottier (1992). La metodología utilizada combina el diseño de estructuras argumentativas y el análisis crítico del discurso con el proceso abductivo de "ida y vuelta" entre la teoría y la práctica (Wodak, 2003:109). Los resultados son: construcción de relaciones argumentativas e identificación de recursos y estrategias utilizadas como operaciones de legitimación/deslegitimación ideológica. Se concluye: 1) los recursos evaluativos, apreciaciones y las modalidades axiológicas utilizadas en juicios prácticos, normativos y éticos son fundamentalmente la base de las estrategias argumentativas que justifican el vínculo entre "problemas y soluciones", y en tal sentido, estas estrategias persuaden sobre "ser" y el deber" de las políticas. 2) los argumentos presentados son cada vez más prescriptivos y presentan niveles coercitivos altos y explícitos en aquellos discursos de carácter técnico; los de discursos de naturaleza política, preferentemente, son implícitos.

Palabras clave: análisis crítico, discurso, argumentación, políticas, neocorporativismo.

Argumentation as troubleshooting in the neocorporativistic speech of venezuelan policies (1989-1994). Critical analysis.

\footnotetext{
* Periodista. Doctorado en Ciencias Humanas. Maestría en Planificación y Gerencia en Ciencia y Tecnología. Líneas de investigación: Análisis del discurso, análisis de públicas. Departamento de Ciencias Humanas. Facultad Experimental de Ciencias. Universidad del Zulia. Investigadora asociada a proyectos de investigación del post-doctorado de Ciencias Humanas. Maracaibo, Venezuela. Correo electrónico: pinedaquinteroal@gmail.com
} 
La argumentación como resolución de problemas en el discurso neocorporativista de políticas venezolanas (1989-1994). Análisis crítico.

\begin{abstract}
The discourse of Development Plans in Venezuela (1989-1994) is critically analyzed in order to unveil the argumentative strategies that ideologically justify the policies formulated by the International Monetary Fund (IMF) in the context of applying the neocorporativist model of the new economy neoliberal The theoretical framework basically contemplates the authors: Maniglio (2017), White (1999), Habermas (1999), Beaugrande and Dressler (1997), Martín y Whittaker (1998), Charaudeau (1992) y Pottier (1992). The methodology used combines the design of argumentative structures and critical discourse analysis with the "round trip" abductive process between theory and practice (Wodak, 2003: 109). The results are: construction of argumentative relationships and identification of resources and strategies used as legitimation / delegitimization operations. It concludes: 1) the evaluative resources, assessments and axiological modalities used in practical, normative and ethical judgments are fundamentally the basis of the argumentative strategies that justify the link between problems and solutions, and in this sense, these strategies persuade about "being "And the duty" of policies. 2) the arguments presented are increasingly prescriptive and with high coercive discursive levels, both explicit and implicit.
\end{abstract}

Key words: critical analysis, discourse, argumentation, policies, neocorporativism.

\title{
Introducción
}

1989 es el año en que se inaugura mundialmente en Venezuela el nuevo proceso de modernización neoliberal en los planes de ajuste macro-estructural aplicados por el Fondo monetario internacional (FMI) y el Banco Mundial (BM). Este proceso que había comenzado en la década de los años 70 estableció partir de 1985 el "neocorporativismo", modelo asociado a una forma de gobernar (gobernanza) en el cual la gestión de funciones de naturaleza pública (educación, salud, vivienda, telecomunicaciones, entre otras) corrientemente atribuidas al Estado pasan a manos del sector privado de la economía, y se rigen por criterios de eficacia y eficiencia para la "resolución de problemas", hecho éste que intenta desplazar a la política (pospolítica') como forma de crear legitimidad e identidad (Marramao, 1989, en Labarriére y col. 2000), (Aguilar,2006). Este intento de desideologizar al estado y la sociedad, algunos autores lo consideran hoy una realidad demostrable en los países desarrollados (Maniglio; 2017).

Es este el contexto de desarrollo de la nueva economía o nuevo capitalismo en el cual se hará un análisis crítico de argumentos contenidos en el VIII Plan Nacional de Desarrollo Económico y Social (PNDES, 1989) y III Plan Nacional de Ciencia y Tecnología (III PNCyT, 1989)2 ${ }^{2}$, suscritos en Venezuela para el período presidencial 1989-1994 como instrumentos de política pública ligados al desarrollo del país. El objetivo del análisis crítico fue develar las estrategias argumentativas que justifican ideológicamente las políticas diseñadas y formuladas por el Fondo Monetario Internacional (FMI) en el contexto de aplicación del modelo neocorporativista de la nueva economía neoliberal.

\footnotetext{
1. Pos-política: intento del neoliberalismo de anestesiar lo político reduciéndolo a una actividad de gestión o gobierno de lo existente, acotado por consensos normativos. Exclusión de la discusión política, y por tanto de la democracia. Véase Mouffe, Chantal (2009). El fin de la política.

2. VIII Plan Nacional de Desarrollo Económico y Social ( VIII PNDES) fue diseñado por el Consejo Coordinador del Plan (CORDIPLAN, 1989);

y III Plan Nacional de Ciencia y tecnología (III PNCT), diseñado y publicado por el Consejo Nacional de Investigaciones Científicas y Tecnológicas (CONICIT, 1990).
} 
Se describen a continuación los lineamientos que sustentaron el proceso de investigación llevado a cabo: a) marco teórico: se utilizaron, fundamentalmente, los aportes teóricos de Maniglio (2017), Serrano y Villalobos (2006), Calsamiglia y Tusón (1999), White (1999), Habermas (1999), Beaugrande y Dressler (1997), Charaudeau (2003, 1992) y Pottier (1992); b) metodología: 1) se analizaron las relaciones argumentativas observadas en el discurso seleccionado aplicando el esquema sugerido por Charaudeau (1992) que consiste en determinar las "aserciones de partida, de llegada y la conclusión".

El modelo de Charaudeau en el contexto de este artículo fue adaptado para explicar el uso de la relación argumentativa como "resolución de problemas" de orden lingüístico comunicativo, esto significa que en cada uno de los argumentos seleccionados se identificará un tema, un problema (aserción de partida), se evaluarán causas, consecuencias, justificaciones del problema que se exhiben como razones constituidas en "ley de paso" (aserción de pasaje: evaluación del problema) para arribar a la resolución o solución del problema (aserción de llegada). El lazo entre la aserción de partida y la de llegada es a través de los conectores que pueden estar presentes 0 ausentes.

2) Luego del diseño de las relaciones argumentativas contenidas en el discurso analizado se efectuó el proceso de interpretación que abarcó la relación argumentación- recursos y estrategias de carácter lingüístico (lexical, sintáctico y semántico) y pragmático.

El análisis interpretativo del discurso realizado es abductivo pues contempla un "proceso de ida y vuelta" entre la teoría y la práctica (Wodak y Meyer, 2003: 53-54,109). d). El corpus 0 unidades de análisis: se seleccionaron algunos textos de los planes VIII PNDES y III PNCyT. Estos textos fueron seleccionados por la analista según explicitaran en el argumento, objeto de análisis, la relación "problema-solución". Lo cual permite observar en la estructura argumentativa las operaciones de cohesión (orden sintáctico) y coherencia (orden semántico) ligadas discursivamente con acciones vinculadas con el "hacer de las políticas públicas" que son sometidas a la interpretación y aceptabilidad de los receptores. En adelante el contenido se ordena en cuerpo (fundamentación teórica y resultados), conclusiones y referencias bibliográficas.

\section{Fundamentación teórica}

\section{El Consenso de Washington (CW): primera y segunda generación conceptual programas de ajuste macroestestructural.}

La aplicación de los planes de ajuste macro-estructurales en Latinoamérica se ha hecho acorde con el acuerdo Bretton Woods, suscrito en 1944 y propiciado por Estados Unidos y Gran Bretaña. El Fondo monetario internacional (FMI), el Banco mundial (BM), el Banco Interamericano de desarrollo (BID) y la Organización del comercio y del desarrollo económico (OCDE) son los actores globales de aplicación del acuerdo mencionado (Martínez y Soto, 2012).

El programa de reformas aplicado en Latinoamérica como respuesta a los efectos de la crisis de la década del 80 del pasado siglo (fracaso del modelo de sustitución de importaciones, bajada de los precios del petróleo, incapacidad para pagar la deuda), formó parte del llamado Consenso de Washington (CW), y fue elaborado por expertos o "tanques pensantes" (los think tanks del Instituto internacional de economía en 1989) conducidos por John Williamson. Esta vinculación entre saber y poder constituye junto con la del sector privado, el trío de alianzas protagónicas del neocorporativismo o nuevo capitalismo. 

venezolanas (1989-1994). Análisis crítico.

El programa de reformas neoliberal inspirado en la economía neoclásica y el modelo político neoliberal hacía énfasis, entre otros, en los siguientes aspectos: disciplina fiscal, reorientación del gasto público, reforma tributaria, liberalización financiera, tipos de cambio, liberalización del comercio, apertura a la inversión directa, privatización, desregulación y asegurar los derechos de propiedad (Martínez y Soto, 2012). El plan no contiene ninguna "receta" vinculada al alivio de la pobreza y al fomento de la equidad, aspectos que sí fueron incluidos en los contenidos del llamado consenso de Washington extendido, segundo plan de reformas económicas suscritas en el 2003 como respuesta a las crisis de1999 y 2001 vinculadas con el fracaso de inversiones en proyecto relacionados con empresas.com y con prácticas de inversiones especulativas en la bolsa de valores (Martínez y Soto, 2012).

El nuevo "cómo lo digo" o discurso de la segunda generación de reformas estructurales ha sido denominado tecno-económico (híbrido entre la tecnología y la economía) o tecnopolítico (híbrido entre la tecnología y la política). En todo caso, lo común es la referencia a la tecnología, bien sea, que los problemas a solucionar tengan carácter económico 0 , en su defecto, político.

\section{El Discurso "neocorporativista": la argumentación en el programa de reformas neoliberales de primera generación.}

La propuesta que vincula la argumentación como forma discursiva con la resolución de problemas se evidencia implícitamente en la metodología seguida por Maniglio (2017), quien estudia la nueva forma de gobernanza europea mediante un análisis del discurso de los organismos multilaterales que aplica el esquema: tema, problema, evaluación, resolución. En este caso, el texto se arma a partir de un problema y se evalúan razones para justificar la forma de darle solución a un problema.

Por considerar que el mencionado esquema anterior es solo una versión que la argumentación puede adoptar debido a su diversidad estructural, se ha asimilado esos elementos en la propuesta de estructura de la relación argumentativa formulada por Charaudeau (1992) que consta de aserción de partida (A1), aserción de pasaje y aserción de llegada (A2) (ver esquema 2, p. 8).

Por otra parte, el análisis de la relación argumentativa incorpora los aportes de White (1999) relacionados con la teoría de la valoración o evaluación que permite identificar los recursos lingüísticos a través de los cuales se expresan, negocian y naturalizan posiciones intersubjetivas e ideológicas del emisor: actitudes (afectos, juicios, apreciaciones). La evaluación de afectos remite a significados ligados al campo de la emocionalidad; los juicios evalúan conductas de las personas en relación con normas sociales y entidades; y las apreciaciones valoran con criterios estéticos y de evaluación social objetos, productos, constructos, políticas, planes, entre otros.

Como sistema interactivo vinculado a la comunicación, el lenguaje está estructurado a diferentes niveles (referencial, lógico conceptual, lingüístico y discursivo) (Pottier, 1992). En este sentido, los argumentos que se analizan en este artículo que configuran el discurso "neocorporativista" observado en el VIII PNDES y III PNCyT atendiendo a la visión sistémica del lenguaje se construyeron con recursos lingüísticos (lexicales, sintácticos, semánticos) y discursivos, entendiendo estos últimos como el punto de enlace entre lo interno de un texto 
(contexto: sintáctico-semántico) y el contexto (situación de comunicación), premisa vinculada a la adecuación del mensaje en situaciones concretas de comunicación (Pineda, 2017).

Es así como el nivel discursivo se identifica con los aspectos pragmáticos, comprometidos con: 1) los procesos de producción del mensaje ligados a la intencionalidad del emisor (propósitos, fines, objetivos, metas; 2) los procesos de recepción e interpretación por parte del receptor relacionados con la adecuación del mensaje y con la situacionalidad, que involucra la situación de comunicación en que se da y recibe el mensaje (Beaugrande y Dressler, 1997).

Los recursos pragmáticos mencionados interaccionan en el discurso con las relaciones de cohesión (conexión de naturaleza sintáctica, gramatical, observada en el texto a nivel superficial) y de coherencia (de naturaleza semántica, conceptual, vinculada al significado, en la estructura profunda) que debe observar un texto como parte del proceso de planificación de la estrategia discursiva que permitirá cumplir con la meta de convencer, justificar, refutar, persuadir. Esta particularidad del discurso argumentativo lo relacionan los autores que estudian la argumentación con su función teleológica (relación medios -fines).

Si se parte de las consideraciones anteriores, atendiendo a la visión pragmática del sistema lingüístico comunicacional se puede plantear que los textos identificados como contenidos del VIII PNDES y III PNCyT son textos híbridos que se mueven entre: a) una supuesta objetividad y neutralidad de argumentaciones racionales fundamentadas en un saber tecnocientífico (un ethos) que apela al intelecto, a la razón, al mundo de la referencia, como modo de discernir sobre un tema, asunto o problema, en cuyo caso domina el discurso referido; y b) la subjetividad que va al mundo interno de emisores y receptores, en cuyo caso domina la emocionalidad (pathos; actitudes, opiniones, apreciaciones, juicios, valores) y los modos discursivos comentado y provocado (Charaudeau, 2003).

Al utilizar la estrategia del ethos se busca convencer a "alguien de algo", sin que el uso de tal estrategia signifique que necesariamente la persona, objeto del convencimiento, cambie de actitud. La otra posibilidad es que el discurso centre su efecto (ilocutivo: "decir algo haciendo algo, decir algo para causar efecto") en la finalidad de persuadir, hacer cambiar de actitud, opiniones, valores de los receptores, etcétera, y se apele a la subjetividad, en cuyo caso se activa el mundo de las emociones, actitudes, sentimientos, sensibilidad (el pathos) (Serrano y Villalobos, 2006).

Ethos y pathos son construcciones retóricas pertinentes para el análisis de una política pública que pueden estar ligados a cualquier modo de organizar un discurso (narrativo, descriptivo, explicativo, argumentativo) (Adam y Lorda, 1999), afirmación válida si atendemos la ibridez de los géneros como forma de entrar combinadamente en cualquier forma organizativa del discurso.

La argumentación ha sido definida de muy diversas maneras por autores tales como Gutiérrez (2002), citado por Calsamiglia y Tusón, (1999), Escandell (1993) y Van Eemeren; Grootendorst (1987, citados en Gutiérrez, 2002: 237,238). Una de las definiciones más intuitivas de argumentación la relaciona con: "aducir argumentos", "dar razones a favor de una determinada conclusión" (Anscombre y Ducrot, 1983, citado en Escandell, 1993: 109). Posteriormente a la definición presentada con anterioridad, los autores mencionan un aspecto nuevo en la definición de argumentación, vinculado con la finalidad persuasiva, así: "(...) un emisor hace argumentación cuando presenta un enunciado o conjunto de enunciados E1 
[argumentos] para hacer admitir otro enunciado o conjunto de enunciados E2 [conclusión] (Anscombre y Ducrot, 1983, citados por Gutiérrez, 2002:237).

De igual manera, según la bibliografía consultada no existe un diseño prototípico de la estructura de argumentación, por tanto, cualquiera de los existentes que se seleccione, es válido, en este sentido: Calsamiglia y Tusón (1999), presentan la estructura más simple para la argumentación monologal; Charaudeau (1992), señala los elementos base de la relación de argumentación; y Toulmin (1958, citado por Calsamiglia y Tusón, 1999: 296, 297), completa el esquema monologal agregando los elementos de garantía ("debido a qué") y de reserva ("a menos qué"). A continuación se observa algunas de las estructuras más utilizadas:

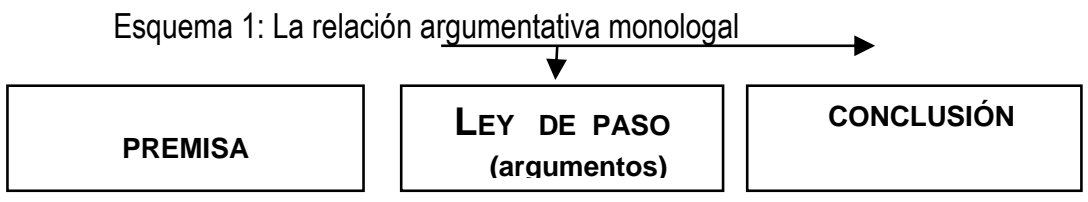

Fuente: Calsamiglia y Tusón, 1999.

Esquema 2: La relación argumentativa

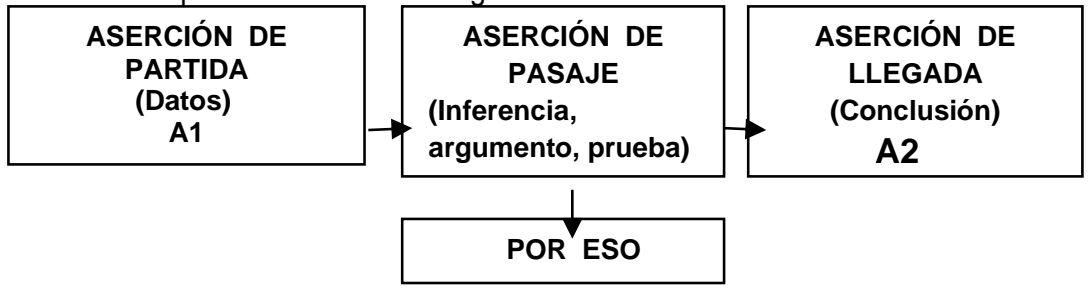

Fuente: Charaudeau (1992).

En relación con el contenido de los esquemas anteriores se señala que la estructura de una relación argumentativa monologal o dialógica suele ser la misma en la mayoría de los autores, solo cambia el nombre o designación de lo que se argumenta: "asunto, tema, problema" de los que parte; o de la conclusión o resolución a la que se llega.

Respecto a la "ley de paso" o aserción de pasaje ("puesto qué"), ésta se relaciona con "argumentos, razones, causas, consecuencias, justificaciones, pruebas, creencias, observaciones, prescripciones" que llevan a la construcción de las inferencias que articulan la premisa o aserción de partida con la conclusión. Esta relación se hace normalmente a través de elementos lingüístico-discursivos denominados conectores, y los cuales "pueden estar o no estar presentes en la relación argumentativa, según sean las necesidades del acto comunicativo concreto" (Gutiérrez, 2002:245) (Montolío, 2001:25,26).

La anterior apreciación es particularmente válida para aquellas relaciones de argumentación donde se trata de "justificar" algo, y por tanto, se le da más importancia a las relaciones de sentido entre las aserciones de partida y de llegada que a la articulación formal mediante conectores (Charaudeau, 1992). 
Además de la definición y diseño de las estructuras argumentativas se requiere establecer que la argumentación cumple dos funciones: una función teleológica vinculada con su carácter de "servir para algo" ("motivar, justificar, explicar, probar, legitimar, autorizar") y una función relacional en su organización interna que vincula "una razón o argumento con una conclusión". Este vínculo que es "su razón de ser" es lo que se denomina finalmente, RELACIóN ARGUMENTATIVA (Gutiérrez, 2002: 242).

Finalmente, se refiere que las estrategias argumentativas (el cómo) pueden definirse como "los procedimientos discursivos que de manera intencional y consciente utiliza el hablante para incrementar la eficacia en el empeño de convencer o persuadir al destinatario en una situación de comunicación donde predomine la argumentación" (Serrano y Villalobos, 2006:60). Las estrategias según esta definición se ligan a la eficacia (lograr el objetivo o meta de convencer 0 persuadir), pero aún más que eso, la eficacia se relaciona textualmente, según el enfoque procedimental con la "facilidad de procesamiento de un texto ligada a la concentración de recursos cognitivos tales como la atención y el acceso a la información en el funcionamiento controlado de las operaciones" (Beaugrande y Dressler, 1997:73).

\section{Textualidad, procesamiento de textos y resolución de problemas.}

Dentro del llamado "enfoque procedimental" o sistémico (interacción entre niveles: relaciones, operaciones) hay dos definiciones de texto que lo señalan como: 1) "un documento de decisiones, selecciones y combinaciones"; 2) como "un sistema cibernético" en el que continuamente se están regulando las funciones constitutivas de sus elementos (Beaugrande y Dressler, 1997:74, 77).

La textualidad y el procesamiento de textos de acuerdo con la formulación de normas de textualidad (cohesión, coherencia y normas pragmáticas vinculadas con la intencionalidad, adecuación y situacionalidad) pueden ser analizados como "una operación formal de resolución de problemas" (Newel y Simon (1972, citados por Beaugrande y Dressler 1997: 77).

Y ¿qué es un problema desde el punto de vista de la textualidad? Según los autores citados un problema es la imposibilidad de recorrer la trayectoria de conexión entre dos elementos (conexión, cohesión). La resolución de un problema, por su parte, está ligada al establecimiento de una trayectoria que conecta sin interrupción el estado inicial de un elemento con el estado meta (estrategia: en la argumentación teleológica, por ejemplo). La relación problema -solución puede ser objeto de un bloqueo o de una interrupción que no permite avanzar hacia la consecución de la meta.

En definitiva, la operación decisiva de "resolución de problemas" es la búsqueda de una conexión entre estados distintos (Beaugrande y Dressler, 1997:77). Si bien esta aplicación la refieren al texto los autores citados, no hay ninguna razón para que los mismos no puedan ser aplicados al accionar de las políticas públicas, en las cuales los análisis pueden seguir las trayectorias entre la observación y diagnóstico de un problema hasta la solución del mismo, lo cual involucra tanto prácticas no discursivas como discursivas, si es que el analista separa las acciones de las operaciones lingüísticas ligadas a su representación, producción e interpretación.

En un enfoque argumentativo basado en la "resolución de problemas" las estrategias relacionadas con el ethos (inteligencia, razón, saber científico-tecnológico) apelan a "argumentos de autoridad, de modelo, de analogía o comparación"; y las del pathos 
La argumentación como resolución de problemas en el discurso neocorporativista de políticas venezolanas (1989-1994). Análisis crítico.

(emocionalidad) se vinculan con "acusación a los oponentes, descalificación, ironía, advertencias sobre implicaciones y consecuencias indeseables", entre otras (Serrano y Villalobos, 2006: 60 a 68).

\section{El discurso "neocorporativista" en el VIII PNDES: diseño de la relación argumentativa e interpretación de los argumentos.}

Dentro de los contenidos del VIII PNDES (1989), se seleccionaron para el análisis los argumentos siguientes:

3.1 El nuevo modelo de apertura internacional de la economía

Esquema 3: La relación argumentativa

(Aserción de partida)

"Economía no

abierta a la competencia internacional"
Razones: consecuencias

(Aserción de pasaje)

\section{Evaluación: juicios}

(ético/normativo) y apreciaciones.

-Estancamiento de la producción

- Condena de los venezolanos al

desempleo y la pobreza.
Resolución/ solución (Aserción de llegada) "Se debe aceptar el proceso de apertura".

Fuente: Elaboración propia, adaptación basada en Charaudeau (1992).

En el esquema 3 se parte de un tema referente a la economía; y su condición de "no estar abierta a la competencia internacional" se considera problema (A1). La evaluación del problema en términos explicativos de sus consecuencias, permite aducir razones que explican el nexo que existe entre A1 y A2 (partida/llegada) en términos de justificación de una determinada acción que conduce a la resolución o solución del problema: "por eso se debe aceptar el proceso de apertura económica internacional".

El recurso lingüístico retórico "se debe" es una modalidad deóntica de grado coercitivo alto $^{3}$, un "tener que hacer" (Pottier, 1992:290), que encierra, en este caso, el posicionamiento subjetivo, ideológico del emisor, quien desde una relación de fuerza persuade al receptor respecto a la conducta que debe asumir "obligatoriamente" ante el problema planteado. Este proceso que puede denominarse de coerción ideológica discursiva (cursiva nuestra) puede estar explícito en el discurso o suponer una implicatura que implica deducir una intencionalidad interpretable por el contexto.

La "coerción ideológica discursiva" puede analizarse desde el constructo denominado "cuadrado lógico semiótico" que según Pottier (1992, establece jerarquías para toda

\footnotetext{
3. Coerción discursiva :Los grados muy alto, alto, medio o bajo de coerción en un discurso considerado como ideológico se pueden evaluar atendiendo los requerimientos del llamado "cuadrado lógico, semiótico" (Pottier, 1992:275 a 293) o del llamado en ciencia política "lo lógico posible como límite de la performatividad sistémica", vinculado con el esquema "ser-deber ser" de las políticas públicas.
} 
organización semántica extraída de las estructuras narrativas y califica en grados (alto, medio, bajo) la coerción ideológica ligada al posicionamiento del emisor en el discurso atendiendo al uso de modalidades de diverso género (existenciales, epistémicas, factuales y axiológicas) (Pottier, 1992:283 a 293). En la ciencia política este esquema se identifica con el "lógico posible" vinculado al "ser y deber ser de las políticas públicas" (Marramao, 1986, citado por Labarriére y col, 2000); al igual que desde la teoría crítica (Habermas, 1999; 540: Tomo 2).

Una vuelta al análisis planteado muestra en el recuadro 3 citado anteriormente, un esquema punteado (en el cual aparece la resolución o solución al problema) que indica que este contenido no está explícito en el mensaje analizado, sino que está implícito, constituyendo así un indicio, una implicatura. Este es un tipo de significado de carácter ostensivo que "hace manifiesta la intención de hacer manifiesto algo"; e inferencial, que se refiere a "un proceso de tipo deductivo que permite otorgar validez a un supuesto sobre la base de otro supuesto" (Sperber y Wilson, 1986, citados por Escandell 1993:134).

Así: "hay que, necesariamente, abrir la economía al mercado internacional" (supuesto 1): porque esto pudiera (existe la posibilidad) significar "desarrollo, encontrar empleo y entrar en la riqueza" (supuesto 2), esta es una razón implícita válida utilizada para persuadir sobre la aceptación obligatoria del proceso de apertura. Si bien, la interpretación es contextual y por tanto, sujeta al mundo de creencias del receptor, la misma ha sido sugerida por la forma discursiva "ostensiva e inferencial" empleada por el emisor.

En el caso analizado el nexo entre A1 y A2 está mediado lingüísticamente por un conector que indica consecuencia: "por eso", que puede estar o no estar presente. En este caso, no aparece en el texto analizado (recuadro punteado), sin que por ello dejemos de entender la intencionalidad del emisor al establecer la relación que existe entre A1 y A2. Además del conector otros recursos lingüísticos se identifican en el aparte correspondiente a la evaluación que da razones que tienen por finalidad persuadir o "hacer creer".

En este sentido, el emisor de este mensaje manifiesta su actitud negativa sobre la economía (proceso) mediante apreciaciones: "la producción está estancada". También emite juicios intelectuales (Pottier 1992:288): a) de carácter ético, relacionado con el efecto que causa en las personas el estado de la economía: "los venezolanos están condenados al desempleo y la pobreza". El estancamiento es "algo malo", inético" (implícitos relacionados con la modalidad axiológica); b) juicios de carácter práctico, pertenecientes al par: fracaso/éxito" (implícito: "si hasta ahora la economía ha fracasado, la apertura asegura el éxito") que justifican por tales razones, que inexorablemente, se debe aceptar el proceso de apertura como solución al problema, no hay más salida. De esta misma forma, se comunican actualmente eventos tales como la globalización, la sociedad del conocimiento, las nuevas tecnologías, el paradigma tecnoeconómico, entre otros.

Apreciaciones, opiniones, juicios y modalidades son elementos que forman parte del proceso de construcción de subjetividad (White, 1999), a través de los cuales se manifiesta la ideología (van Dijk, 2003) legitimadora de las acciones comentadas por el emisor.

Otro comentario final. se relaciona con el tipo de racionalidad instrumental que aun acompaña a la racionalidad sistémica y que aún lleva implícito el discurso neocorporativista: el mensaje busca producir un efecto, su carácter perlocutivo se traduce en persuadir y producir cambios de opinión en los receptores mediante la estrategia de afectar sus emociones (pathos); los contenidos de lo que se dice o las razones con las que se trata de convencer a los 
oponentes se refieren a la eficacia de la regla de acción y no a la verdad o falsedad de los de los enunciados. Las explicaciones que se dan son solo indicadoras de que en determinadas condiciones una acción instrumental puede tener o haber tenido éxito. Esto, según Habermas (1999) desde el punto de vista de la racionalidad es característico de acciones teleológicas o estratégicas que mutan hacia el modelo explicativo de la sociedad moderna ligada a la "resolución de problemas", y no a la objetividad o verdad de los enunciados como originalmente promovía la acción teleológica o instrumental (fines-medios).

\section{El rol del estado en el nuevo modelo de apertura económica globalizada.}

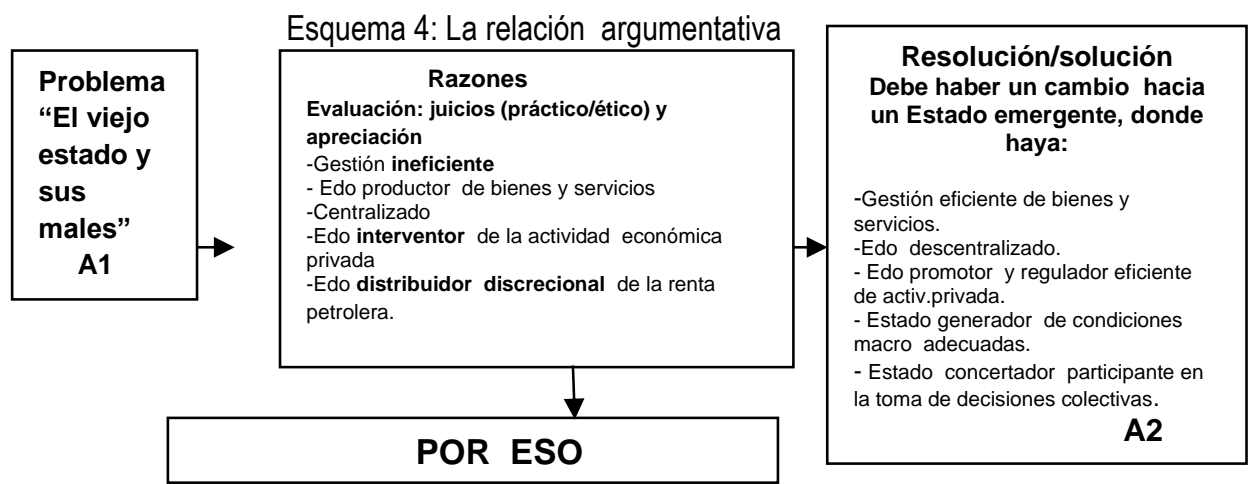

Fuente: Elaboración propia, adaptación basada en Charaudeau (1992).

En este caso, el argumento tiene como tema el "viejo estado" y como problema sus supuestos males prevalecientes hasta finales de la década del 80 (aserción de partida: A1). La resolución o solución (aserción de llegada A2) es el advenimiento de un Estado emergente, previsto en el plan de reforma macroetructural, que representa todo lo contrario, es decir, es un "estado virtuoso", "bueno". La oposición entre los dos tipos de Estado es evaluada (axiológicamente) desde "juicios intelectuales prácticos (éxito/fracaso) y éticos (malo /bueno). Es pertinente aclarar que si bien los juicios evalúan conductas de las personas, esa variante de manifestación de actitud se aplica también para evaluar entidades (White, 1999), en este caso, el Estado, del cual también se emiten apreciaciones ("gestión ineficiente").

La evaluación práctica y ética de los atributos del viejo estado se convierten en razones (aserción de pasaje) que permiten hacer la inferencia "por eso", un conector consecutivo que permite vincular (A1 con A2), el problema con la resolución.

Las razones que llevan de A1 a A2 están basadas "ideológicamente" en diferenciaciones, oposiciones entre el viejo estado al que habría que reformar y un supuesto estado emergente que sería la propuesta dentro del modelo de desarrollo que intentaba aplicarse. En este sentido, a través de un léxico polarizado (positivo / negativo) (van Dijk, 2003) se establecieron diferencias entre los tipos de Estado: eficiente /ineficiente; centralizado/descentralizado; interventor/promotor-regulador; y finalmente, Estado distribuidor de la renta/Estado concertador de decisiones colectivas. 
A través del léxico polarizado y de la expresión de un saber técnico (ethos) se intentó discursiva e implícitamente convencer sobre la necesidad de cambiar el Estado mediante "el ahuecamiento de sus más importantes funciones", paso inicial de la estrategia imperial de eliminar los Estados-nación. Es así, como según este VIII PNDES para lograr los objetivos de internacionalización de la economía, el viejo estado debía renunciar a su papel de ser el ente rector de la economía debiendo acomodar sus nuevas y recortadas funciones a los intereses del modelo emergente de la economía globalizada propuesto por los organismos multilaterales, financistas del VIII PNDES y de la renegociación de la deuda externa.

\section{La reforma política y administrativa de la gestión del estado}

Esquema 5: La relación argumentativa

\begin{tabular}{|c|c|c|}
\hline $\begin{array}{l}\text { Problema } \\
\text { "Deficiente } \\
\text { gestión } \\
\text { política y } \\
\text { administrati } \\
\text { va del } \\
\text { Edo". } \\
\qquad \text { A1 }\end{array}$ & $\begin{array}{l}\text { Razones: consecuencias } \\
\text { Evaluación: juicios } \\
\text { (normativo/ético) y apreciaciones } \\
\text {-Ausencia de rentabilidad en las } \\
\text { empresas administradas por el Edo. } \\
\text { - Gran crecimiento de los entes } \\
\text { centrales. } \\
\text { - La gestión pública no responde a } \\
\text { los problemas de las comunidades. } \\
\text { - Centralización de los recursos y } \\
\text { tomas de decisión de la industria } \\
\text { petrolera }\end{array}$ & $\begin{array}{l}\text { Resolución o solución: } \\
\text {-Hay que adelantar el } \\
\text { proceso de privatización } \\
\text { de las empresas. } \\
\text {-Hay que adelantar el } \\
\text { proceso de } \\
\text { descentralización de la } \\
\text { toma de decisiones } \\
\text { A2 }\end{array}$ \\
\hline
\end{tabular}

Fuente: Elaboración propia, adaptación basada en Charaudeau (1992).

En este caso, las argumentaciones parten del tema "gestión deficiente del Estado" que se constituye referencialmente en el problema (A1) cuyas consecuencias justifican mediante razones el pasaje de A1 a A2 usando el enlace o conector consecutivo "por eso", que lleva a la resolución o solución. La evaluación en este caso se centra en la gestión de la cual se hacen apreciaciones: "no son rentables, está burocratizada, no resuelve problemas, centraliza recursos y tomas de decisión". Dado que la gestión es llevada por personas, se afirma que indirectamente, implícitamente (implicaturas), se hace también un juicio intelectual de carácter normativo y ético sobre los gestores, basado en el par lo incorrecto/lo correcto; virtud/vicio; eficientes/ineficientes. La gestión del Estado es evaluada como incorrecta, viciada, ineficiente, fracasada. Ideológicamente esta forma de evaluar que descalifica a lo que nos oponemos se identifica con el pathos.

Entre los recursos valorativos observados están la adjetivación; también negaciones que expresan ideológicamente la forma como se presentan las acciones de un estado de cosas (la gestión), a las cuales se oponen las medidas a aplicar en el proceso de reforma estructural ("la gestión pública no responde a los problemas de las comunidades"). 
En cuanto a la resolución o solución se persuade al receptor mediante modalidades existenciales del tipo óntica que se mueven en el eje "lo real, lo imaginario, lo aparente"; y del tipo alética, que lo hace en el eje:"imposible, posible, necesario, inevitable" (Pottier, 1992:283). Así, mediante el uso de estas modalidades el emisor del mensaje legitima los procesos, acciones o medidas de las que habla reafirmando: su "ser", su existencia real y "su deber ser", tal y como se expresa en los enunciados siguientes: "hay que adelantar el proceso de privatización (...), "hay que adelantar la descentralización", el enunciado no deja lugar a dudas: dadas las razones, lo real, son ("ser": modalidad existencial óntica) las medidas o acciones que "hay que aplicar" necesaria e inevitablemente (modalidad existencial alética): "privatizar y descentralizar".

Este "hay que hacer", es suscrito discursivamente con un grado alto de convencimiento de lo que hay que hacer, de lo que es necesario hacer, pero bajo en cuanto a la obligatoriedad de ejecutar la acción para solucionar el problema, si es que se atiende al constructo "ser y deber ser" de las políticas, que en el discurso tecno-económico privilegia la existencia o "ser", lo real de las soluciones a un problema (modalidad existencial óntica).

De esta forma, los argumentos justificaban la reforma política del estado, de la gestión pública y privatización de las empresas públicas, mediante la descalificación y satanización de la actividad planificadora y gerencial del Edo, en un intento por desmontar, descalificar 0 desnaturalizar el estado -nación y en su defecto, legitimar el nuevo estado neocorporativo neoliberal.

\section{La crisis y los actores en el juego de la economía}

Esquema 6: La relación argumentativa

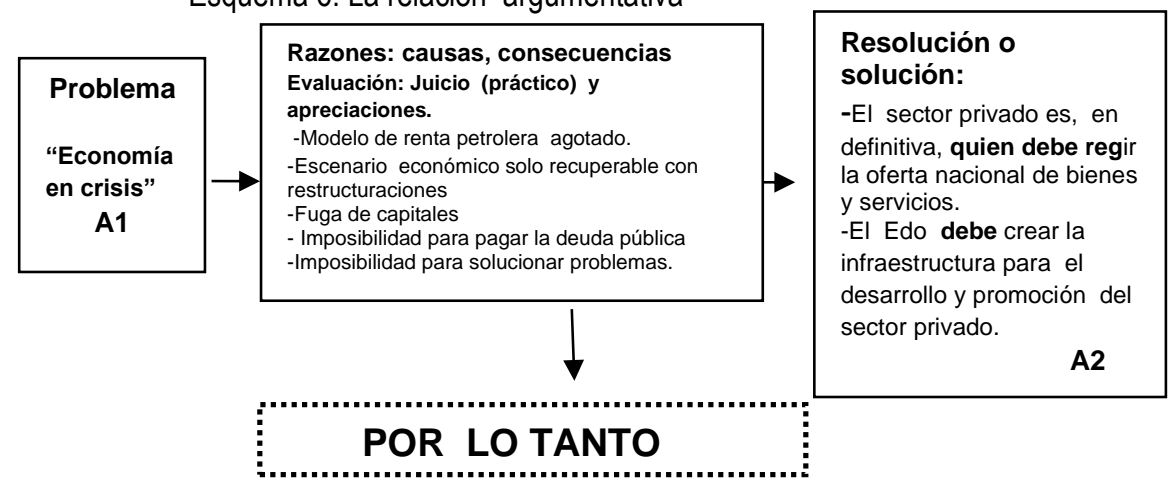

Fuente: Elaboración propia, adaptación basada en Charaudeau (1992).

El tema del que se habla en este caso es sobre la crisis económica, problema que se explica por causas: contextuales (agotamiento del modelo petrolero, fuga de capitales) y consecuencias derivadas de la gestión: (imposibilidad para solucionar los problemas del país y para pagar la deuda, escenario económico solo recuperable con restructuraciones). Estas razones justifican la solución: repartir las funciones entre los actores según el eje: sector privado ofertante de bienes y servicios/el estado promotor y creador de condiciones para el desarrollo del sector privado. 
El nexo entre la causa y la resolución o solución es un conector consecutivo del tipo "por lo tanto". Los recursos lingüísticos son de carácter subjetivo y revelan la actitud del emisor respecto al problema y su solución, en tal sentido, implícitamente hay juicio de carácter práctico respecto al fracaso del Estado como entidad que ha tenido imposibilidad para pagar la deuda externa y para solucionar los problemas del país.

También hay apreciaciones ("hay deficiente gestión administrativa del Edo"), "modelo petrolero agotado") y modalidades de diversa naturaleza, entre ellas la modalidad existencial alética ("imposibilidad para pagar la deuda, imposibilidad para solucionar los problemas") que se mueve en el eje "imposible/posible/ necesario" (Pottier, 1992:283), lo inevitable. Igual uso de esa modalidad se hace en el enunciado "escenario económico "solo" recuperable con reestructuraciones", en el cual la oferta del paquete económico se ofrece como la única opción, lo inevitable para mejorar la economía, según la interpretación del implícito o implicatura que contiene el enunciado: "no hay otra opción, esa es inevitablemente, la necesaria"

Respecto a la conclusión se evidencia el uso de la modalidad deóntica que indica obligatoriedad (alto grado) vinculada con un "deber" y un "tener que hacer" (Pottier, 1992: 290): ("es el sector privado quien debe regir la oferta de bienes y servicios"; "el Estado debe crear la infraestructura... (...).

Se deduce del argumento anterior que el "juego de la economía" propiciado por el nuevo modelo neocorporativista vigente para la época se concentra entre empresarios, una élite de tecnócratas y un estado debilitado en sus funciones. Se excluyó así a la mayoría del país, quien aparece mencionada en el PNDES, entre otros, como "grupos vulnerables, sectores menos favorecidos, estrato poblacional" que debían ser atendidas por el Estado como ente rector exclusivo de la política social. La masa se invisibiliza mediante recursos discursivos usados ideológicamente y catalogados como eufemismos (van Dijk, 2003) que mitigan su exclusión mediante diferentes formas de presentación ("grupos vulnerables", "sectores menos favorecidos").

\section{El discurso neocorporativista del III PNCyT: diseño de la relación argumentativa e interpretación de los argumentos.}

El III PNCyT (CONICIT, 1990) suscrito durante el segundo mandato de Carlos Andrés Pérez, inauguró de la mano de uno de sus gestores el fin de una década que completaba 30 años de gobiernos de democracia representativa; una sociedad económicamente empobrecida y un país sin rumbo social y cultural. Son estos, resumidamente, algunos de los elementos coyunturales, situacionales, que se mencionan para explicar la pertinencia del III PNCyT, y en cuya concreción participaron grupos de especialistas sectoriales en representación de los organismos e instituciones que conformaban-para ese entonces-el Sistema Científico y Tecnológico Nacional.

El Consejo Nacional de Investigaciones Científicas y Tecnológicas (CONICIT) diseñó el III Plan de CyT tomando muy en cuenta la existencia de vertientes fundamentales contenidas en el VIII PNDES, entre ellas: las que corresponden a la nueva política económica, descentralización del Sector de CyT y la incorporación del desarrollo de las nuevas tecnologías, cuya pertinencia en el decálogo neoliberal las asociaba tempranamente al trío poder-sabersociedad del conocimiento. Se describen a continuación dos aspectos básicos mencionados en el PNCyT. 
La argumentación como resolución de problemas en el discurso neocorporativista de políticas venezolanas (1989-1994). Análisis crítico.

\section{Integración de políticas y disminución de la "brecha tecnológica".}

\section{Esquema 7: La relación argumentativa}

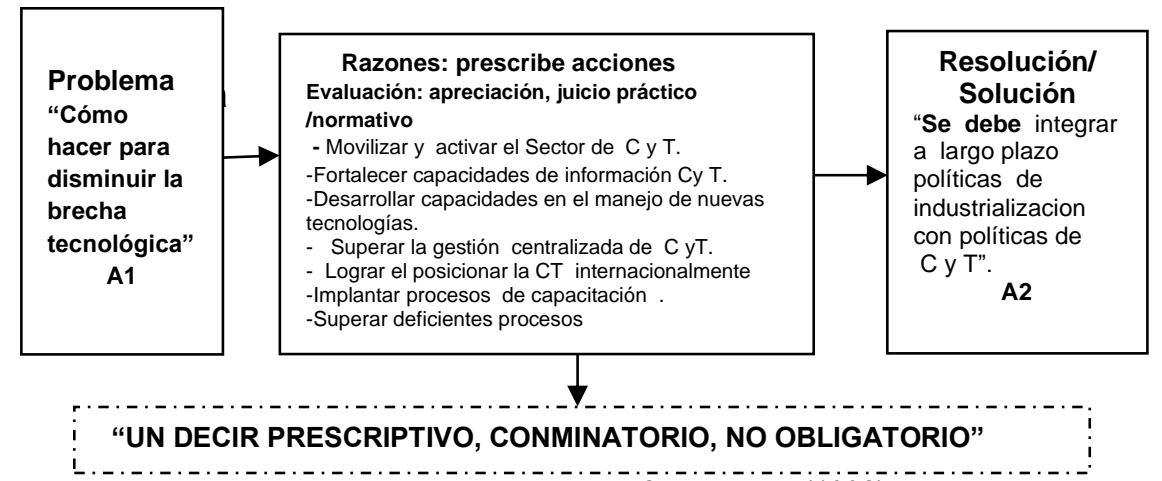

Fuente: Elaboración propia, adaptación basada en Charaudeau (1992).

En el esquema 7 se presenta como tema "la brecha tecnológica" y como problema qué estrategia aplicar para disminuirla (aserción de partida A1); luego, en la aserción de pasaje se prescriben una serie de acciones (movilizar, fortalecer, desarrollar, superar, lograr, implantar) que formarán parte de la estrategia a recomendar para solucionar el problema, tal y como se evidencia en la aserción de llegada (A2): "se debe integrar a largo plazo políticas (...). La evaluación se hace mediante apreciaciones explícitas sobre las políticas públicas que deben aplicarse para mejorar el sector de ciencia y tecnología (SCT). También implícitamente hay juicios, se interpreta que lo expresado por el emisor posiciona la idea de lo que él considera "normativamente correcto", y desde el punto de vista práctico "oportuno, exitoso".

La prescripción es obligatoria ("no solo recomienda, anima o sugiere hacer algo, sino que "obliga o prohíbe"): "alguien está obligado a hacer algo", "alguien tiene que hacer o no hacer algo) (Pottier, 1992), es decir, tiene un grado coercitivo alto. Los recursos lingüísticos utilizados en el "decir obligatorio o prohibitivo de acciones" son verbos en infinitivo ("movilizar, lograr"), que expresan la acción del mismo de manera abstracta. En su mayoría los verbos utilizados pertenecen al área de la actividad ("lograr, superar") (Franco, 2007), y se vinculan con un "hacer" (voluntario o involuntario) y con un "actuar" obligatorio.

La resolución o solución (A2) que da cuenta de la estrategia, por su parte se vincula discursivamente con el uso de la modalidad deóntica "debe" que implica, entre otros, la justificación de la conexión entre el problema y la solución; "alguien" (agente degradado, oculto, "debe") debe prescriptiva (menciona la conducta a llevar a cabo) y obligatoriamente (grado de coerción) aplicar la estrategia diseñada. El agente, actor o actante como elemento que aplicará la estrategia está borrado, ausente, mediante el uso del "se", forma enunciativa delocutiva característica del discurso tecnocientifico vinculada con la objetividad, neutralidad, pero que en este caso adquiere, además, la presunción de eludir responsabilidades por parte de los agentes implicados en el diseño, aplicación y evaluación de la estrategia. 
Otro aspecto que se observa en el esquema argumentativo neocorporativista es la parataxis (Calsamiglia; Tuson, 1999), recurso lingüístico ligado a la ausencia de conectores que vinculen la formulación del problema con la solución. Este recurso ha sido identificado por Fairclough (citado en Wodak y Meyer, 2003:195), en sus investigaciones sobre el discurso neoliberal y la nueva economía.

Finalmente, mediante el saber (ethos) del cual hace gala el emisor para posicionar sus objetos de conocimiento en este discurso, se intenta convencer al receptor. Esta estrategia ha sido calificada en la gramática de la legitimidad suscrita por van Leeuwen (citado por Martín y Whittaker, 1998), como racionalizadora ya que especifica las estrategias ligadas a un saber ya conocido y aplicado (en este caso el de la planificación de políticas públicas).

\section{El problema estratégico y la formulación de políticas}

\section{Esquema 8: La estrategia argumentativa}

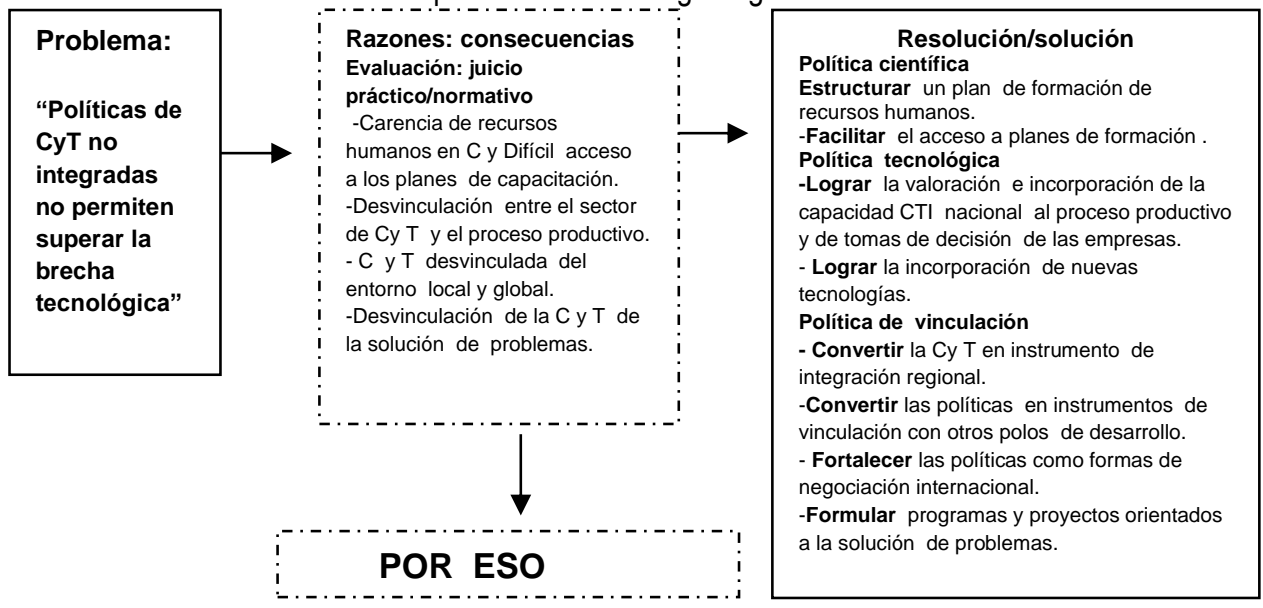

Fuente: Elaboración propia, adaptación basada en Charaudeau (1992).

En este esquema argumentativo se habla de las políticas de ciencia y tecnología, y se presenta como problema el impacto que su desintegración tiene sobre la no superación de la brecha tecnológica (A1). Luego se pasa directamente a la aserción de llegada (A2) o resolución o solución del problema. Allí se prescriben, se hacen apreciaciones sobre las conductas que deben seguirse para lograr solucionar el problema: "estructurar, facilitar, lograr, convertir", todos ellos mediante la forma verbal del infinitivo expresan una actividad vinculada a un proceso, a un hacer, a un actuar.

A diferencia de la estructura argumentativa que le precede en este análisis no se mencionan las consecuencias de la no integración de las políticas, se elide, ésta es una estrategia que se utiliza para evitar hablar explícitamente de aspectos que pudieran resultar conflictivos, inconvenientes, por eso se evitan, y solo se puede llegar a ellos a través de los procesos de ostensión e inferencia ligados a las implicaturas, según consideran Sperber y Wilson (citados por Escandell, 1993:134), cuya construcción e interpretación como sabemos es 
La argumentación como resolución de problemas en el discurso neocorporativista de políticas venezolanas (1989-1994). Análisis crítico.

marcadamente contextual. Por estas razones en el esquema las razones aparecen en un recuadro punteado. Igual sucede con la ausencia del conector que justificaría el pasaje de A1 a A2. Los juicios intelectuales implícitos (razones) en la evaluación del problema son de carácter práctico (fracaso) y normativo (lo incorrecto) y se refieren a la entidad: Sector de ciencia y tecnología.

Finalmente, en este caso el ethos ligado al saber racional práctico de los formuladores de la política es el marco que legitima las acciones expresadas de manera abstracta por los verbos, catalogados en su mayoría como verbos de actividad, ligados a procesos (Franco, 2007).

\section{Conclusiones}

1. La argumentación como "resolución de problemas" es una estrategia discursiva adecuada para el estudio de los planes de reformas macroestructurales. Las razones para tal afirmación son: 1) se ajusta perfectamente al carácter sistémico del discurso de la nueva economía, y su constelación de discursos híbridos; 2) el uso del cuadrado lógico o "lógico posible" para calificar los grados de coerción ideológica da fiabilidad a la interpretación de resultados.

2. Hay un giro pragmático en las relaciones argumentativas del discurso tecnocorporativista o tecno-económico que favorece la evaluación de acciones, procesos y conocimientos mediante juicios intelectuales de carácter ético, normativo y práctico y la valoración de efectos y apreciaciones. Estos recursos explican la relación entre los problemas y las soluciones a través de la aplicación de "racionalizaciones, autorizaciones y normas" que ideológicamente son utilizadas para la legitimación/deslegitimación y naturalización de los contenidos del Plan de reformas macroesructurales y de las políticas sugeridas y recomendadas para resolver una situación.

3. Los recursos y las estrategias utilizadas en la configuración de las relaciones argumentativas son de variada naturaleza. Las que se identifican con la emocionalidad del hablante (pathos), contribuyeron con la legitimación de creencias y de valores que tienden a persuadir y a promover el cambio de actitudes en los receptores y en tal sentido, son ideológicas.

Las vinculadas con la alianza-poder saber, característica de la nueva gobernanza neoliberal, funcionaron mediante prácticas autorizadas que involucran a diversos actores e instituciones. La racionalidad de las prácticas se centró en la eficiencia, en el logro de una meta, el éxito, los resultados, sin que para ello fuera menester la verdad del conocimiento que se comunica ni las consecuencias o riesgos de las acciones que promovía el discurso y que validaban o no la aplicación de una solución.

Las razones que se argumentaron en el diseño del primer plan indican que en ciertas circunstancias la aplicación de la solución a un problema guiado por la racionalidad instrumental "debía tener o haber tenido éxito". Esto es lo que explica el carácter prescriptivo (conminatorio) del discurso de las políticas públicas aplicadas y la de jerarquías ligadas a la obligatoriedad de ciertos valores (un "tener que hacer" o "no hacer") expresado explícita (tecnodiscurso) o implícitamente (discurso tecnopolítico).

4) En Venezuela el proceso de coerción ideológica para la aceptación de las políticas de ajuste se hizo mediante un discurso con diferentes grados de manipulación ideológica de valores asociados al uso de las modalidades, preferentemente deónticas, ("deber-ser") que expresan:1) acciones obligatorias (grado alto) cuya ejecución lleva "inexorablemente" al éxito 0 al fracaso 
(ver esquemas: $3,4,7) ; 2$ ) acciones que prescriben conductas con bajos grados de obligatoriedad (esquema 5); y 3 ) acciones no prescriptivas (esquema 8). Esta es una diferencia con la forma como el discurso neo-corporativista, según los autores citados, se está aplicando en Europa, países en donde la tecnificación creciente de la economía promueve la post-política.

\section{Referencias Bibliográficas}

Adam, Jean y Lorda, Clara (1999). Lingüística de los textos narrativos. Ariel. España.

Aguilar, Luis (2006). Gobernanza y gestión pública. Fondo de cultura económica. México.

Beaugrande, Robert y Dressler, Wolfgang. (1997). Introducción a la lingüística del texto. Ariel. España.

Calsamiglia Helena y Tusón, Amparo (1999). Las cosas del decir. Ariel. España.

Charaudeau, Patrick (1992).Grammaire du sens et de l'expression. Hachette. Francia.

Charaudeau, Patrick (2003). El Discurso de la información. Gedisa. España.

Consejo Coordinador del Plan (CORDIPLAN) (1989). VIII Plan nacional de desarrollo económico y social. Venezuela.

Consejo Nacional de Investigaciones Científicas y Tecnológicas (CONICIT) (1990. III Plan Nacional de Ciencia y Tecnología. Venezuela.

Escandell, María (1993). Introducción a la pragmática. Anthropos. España.

Franco, Antonio (2007). Gramática comunicativa. Colección textos universitarios.

Vicerrectorado Académico de Universidad del Zulia. Venezuela.

Gutiérrez, Salvador. (2002). De pragmática y semántica. Arco/libros. S.L. España.

Habermas, Jürgen (1999). Teoría de la acción comunicativa. Tomo I y II. Taurus. España.

Labarriere, Jean Louis y Lazzeri, Christian; Marramao, Giacomo y otros (2000). Teoría política y comunicación. Gedisa. España.

Maniglio, Francesco (2017). El discurso tecnopolítico de la gobernanza europea: un análisis crítico del discurso (ACD) de las políticas post-Lisboa. Revista Araucaria. Volumen 19, № 37. España. (Pp. 327-351).

Martín, Luisa y Whittaker, Rachel (1998): poder decir o el poder de los discursos. Ediciones de la Universidad autónoma de Madrid. España.

Martínez, Rubí y Soto, Ernesto (2012). El consenso de Washington: la instauración de las políticas neoliberales en América Latina, Revista Política y cultura. Volumen 37, №37. México. (Pp. 35-64).

Montolío, Estrella (2001). Conectores de la lengua escrita. Ariel. España.

Pineda, Alicia (2017).Comunicar la tecnociencia: una propuesta desde el análisis de sus prácticas discursivas. Editorial académica española .España.

Pottier, Bernard (1992). Teoría y Análisis en lingüística. Gredos. España.

Serrano, Estela y Villalobos José (2006). La argumentación discursiva escrita. Publicaciones del Vicerrectorado académico de la Universidad de los Andes. Venezuela.

Van Dijk, Teum (2003). Ideología y Discurso. Ariel. España.

White, Peter. (1999) The Appraisal website:the language of actitude and interpersonal positioning. Extraído de http://www.grammatics.com/appraisal/SpanishTranslationppraisalOutline.doc consulta: 03/06/2013.

Wodak, Ruth y Meyer, Michel, (compiladoras). (2003). Métodos de análisis crítico del discurso. Gedisa. España. 